\title{
The Reality of Administrative Empowerment among the Recently Employed Administrators in the Intermediate Schools
}

\author{
Mona A. Alfadli ${ }^{1} \&$ Sarah M. Al-Mehaisen ${ }^{2}$ \\ ${ }^{1}$ Educational Planning and Administration, University of Jeddah, Saudi Arabia \\ ${ }^{2}$ King Abdul Aziz University, Saudi Arabia \\ Correspondence: Mona A. Alfadli, Educational Planning and Administration, University of Jeddah, Saudi Arabia.
}

Received: January 31, 2019

doi:10.5539/ies.v12n6p120
Accepted: March 8, $2019 \quad$ Online Published: May 29, 2019

URL: https://doi.org/10.5539/ies.v12n6p120

\begin{abstract}
The current study aims at identifying the reality of administrative empowerment among administrators recently employed in the intermediate schools of Riyadh Al-Khabra city, Saudi Arabia, from their perspective. The descriptive survey and comparative approach were applied to (89) administrators recently employed in the intermediate schools of Riyadh Al-Khabra. A five-domain questionnaire was developed to measure the dimensions of empowerment, including delegation of authority, self-motivation, teamwork, personal development and effective communication. The study resulted in a medium level of administrative empowerment among the recently employed administrators in the intermediate schools of Riyadh Al-Khabra. Authority delegation ranked the first, followed by teamwork, effective communication, self-motivation and personal development, respectively. Academic qualification had an ineffective impact on the administrative empowerment of the recently employed administrators. The study recommended supporting the application of the concept of empowerment through disseminating the culture of empowerment in the educational field, diagnosing the relevant organizational constraints, boosting confidence, improving communication among administrators, encouraging teamwork, affording communication channels between administrators and the respective educators and reconsidering the incentive system, administrators' titles and job description based on academic qualification.
\end{abstract}

Keywords: administrative empowerment, recently employed administrators, intermediate schools

\section{Introduction}

Educational institutions in most countries are undergoing a series of administrative reforms to enhance the quality of learning outputs. These reforms cover all the human elements of the educational process, since the actual quality of education depends primarily on the staff who perform the assigned tasks and activities. Therefore, they represent the key engine of the institution and its most important productive resource. In other words, human resources are the axe of the modern administrative movements.

Literature refers to empowerment as a principal factor that reveals the effective aspects of the work environment, such as delegation of authority, self-motivation, teamwork, personal development and effective communication. Wilkinson beliefs that empowerment is the best guarantee for the vitality and continuity of any organization. It contributes to raising morale and satisfaction among employees as they have the opportunity to show their abilities and to gain the management's appreciation and trust (Asuwai \& Atta'ani, 2013).

Alattar (2012) recommended the importance of disseminating the culture of administrative empowerment and enhancing its dimensions and values. Anafisah (2011) said that the leading institutions recognize that attention to the human element is the way to compete and achieve excellence. Accordingly, employee empowerment represents an essential element for institutional success in the Arab world, especially in the face of challenges and changes.

Abdul Khaliq (2011) reached a relationship between empowerment and organizational citizenship among employees. Arrqab (2010) recommended paying attention to the personal and professional needs of employees and encouraging managers to activate delegation and empowerment.

Recently, the Ministry of Education in Saudi Arabia has paid more attention to administrative empowerment. The Conference of Administrative Leadership held in Riyadh in 2014 laid an emphasis on the significance of administrative empowerment. In a seminar on the trends and needs of scientific research in the field of public 
education development in Saudi Arabia, Adduraihim (2014) asserted that empowering the supportive cadre is the way to achieve the strategic vision of the Ministry of Education. The strategic foundations for the future vision of public education development up to 2023 focus on empowering schools to manage the development process according to the circumstances of each region (Adbeai, 2014).

In Saudi schools, numerous administrators are regularly appointed, as one of the main pillars of school management. Administrative empowerment is the way to reduce administrative bureaucracy and enhance participation to improve services and performance (The organizational guide for public schools, 2013).

The focus of this study is on the dimensions of empowering the recently appointed administrators, such as training, personal development, motivation and delegation, teamwork and communication.

\section{Literature Review}

Ashalan and Kaki (2014) revealed that empowerment support, from faculty members' perspective, was not affected by the academic qualification variable. It concluded that there is a defect in empowerment support because of lack of training, centralization, traditional administrative procedures, limited delegation, rigid regulations and individual work.

According to Adbeai (2014), there was a high degree of school principals' empowerment as appeared in delegation, motivation, teamwork, continuous professional development and communication. The sample responses showed statistically significant differences at the level of $\alpha \leq 0.5$ for problems that limit empowerment based on the academic qualification variable.

Alfaez (2014) concluded that there was a medium degree of administrative empowerment among leaders. There were statistically significant differences at the level of $\alpha \leq 0.5$ concerning the impact of academic qualification on the level of empowerment from leaders' viewpoints.

Asuwai and Atta'ani (2013) showed that the level of administrative empowerment among school principals was high. The sample responses showed no statistically significant differences in the level of administrative empowerment due to the academic qualification variable. Jabir (2012) concluded that there was a high degree of administrative empowerment among pricipals with a medium degree of delegation, participation in decision-making and incentives. There were no statistically significant differences in the sample average responses to administrative empowerment based on academic qualification.

Alattar (2012) showed that employees in Al-Azhar and Islamic universities highly agree to support administrative empowerment. There were no statistically significant differences at the level $\alpha \leq 0.5$ in the effect of years of experience on administrative empowerment.

Masoud (2012) concluded that there was a very high degree of administrative empowerment among school principals in the north of the West Bank. There were no statistically significant differences in the degree of administrative empowerment and performance development among school principals due to the academic qualification variable.

Anafisah (2011) resulted in a high level of administrative empowerment among administrators at King Saud University. There were statistically significant differences between empowerment awareness and job satisfaction attributed the academic qualification variable. Almaani and Akhu Arshedah (2009) indicated a medium degree of empowerment and no statistically significant differences in employee perceptions of the concept of empowerment attributed to demographic characteristics, including qualification.

Weshah (2012) revealed that administrative empowerment was moderate and that there were statistically significant differences in administrative empowerment, favoring the holders of postgraduate studies. Lau (2010) found a high degree of organizational support and administrative empowerment. Demographic characteristics affect administrative empowerment, in favor of higher academic qualification. Comm and Mathaisel (2005) showed a high degree of empowerment and highlighted its importance in achieving university success and excellence. University change and innovation is based on active initiatives and leadership empowerment enhanced by good incentives, personal appreciation as well as financial and moral support for employees.

It can be concluded that the literature of administrative empowerment in the field of education has covered various samples, including principals, teachers and employees in schools and universities. However, no previous study addressed the reality of administrative empowerment among recently employed school administrators. The current descriptive study contributes to enhancing quality assurance and continuous development in schools.

\subsection{Problem Statement}

In modern administrative trends, administrative empowerment is essential for the development of staff. As 
previously stated, several previous studies and conferences have recommended employee empowerment, delegation and enhancing belongingness to the organization. Adbeai (2014) and Alattar (2012) suggested conducting more research about administrative empowerment. The problem of the current study is to identify the reality of the administrative empowerment among the recently employed administrators in the intermediate schools of Riyadh Al-Khabra. It can be formulated in the following main question:

What is the reality of administrative empowerment among the recently employed administrators in the intermediate schools of Riyadh Al-Khabra?

It is divided into the following sub-questions:

1) What is the degree of administrative empowerment of the recently employed administrators in the intermediate schools of Riyadh Al-Khabra from their perspective?

2) Are there statistically significant differences in the degree of administrative empowerment due to the academic qualification variable from the recently employed administrators' perspective?

\subsection{Hypothesis}

There are no statistically significant differences at the level of $(\alpha \leq 0.05)$ in the average degree of administrative empowerment among the recently employed administrators due to the academic qualification variable.

\subsection{Objectives}

The current study contributes to improving administrative empowerment among the recently employed administrators in educational institutions through identifying the degree of administrative empowerment among the recently employed administrators in the intermediate schools of Riyadh Al-Khabra. It also aims to reveal the difference in the perceived degree of administrative empowerment due to the variable of academic qualification.

\subsection{Significance}

The current study is of great importance for administrators, school principals, educational supervisors, educational institutions and officials. It contributes to raising administrators' awareness of administrative empowerment, its dimensions and its role in developing work and improving performance. It also helps school principals recognize the importance of supporting administrative empowerment through delegation, boosting confidence and encouraging teamwork. Educational institution and supervisors can support administrative empowerment through affording the required training courses, holding meetings to exchange information and experiences, encouraging communication and spreading the culture of empowerment in the educational field. The current study also benefits officials in the Ministry of Education as it identifies the reality of administrative empowerment among administrators, so they can improve the educational system through providing an adequate organizational structure and reconsidering the incentive system.

\subsection{Limitations}

Objective limitation: identifying the reality of administrative empowerment among the recently employed administrators in the intermediate schools of Riyadh Al-Khabra through five dimensions: delegation of authority, self-motivation, teamwork, personal development and effective communication.

Temporal limitation: the second semester of the academic year 2014/2015.

Human limitation: the recently employed administrators in the intermediate schools of Riyadh Al-Khabra graduated in Teacher Training Institutes, Middle Colleges and Faculties of Education and assigned to administrative posts by the Supreme Order in 2014 and 2015.

\section{Definition of Terms}

Administrative Empowerment: the participation of administrators in the administrative tasks of the school through enabling the delegation of authority and responsibilities, teamwork, motivation, personal development and effective communication.

\section{Conceptual Framework}

Human resources management is a critical issue, because man is responsible for the success or failure of any institution. Therefore, attention has been given to self-leadership and self-motivation much more than the other sources related to money, technology, structure and design (Mulham, 2009). The purpose of the current study is to shed the light on administrative empowerment and some of its aspects, including the concept of empowerment, the significance of empowerment and empowerment dimensions and characteristics. 


\section{The Concept of Empowerment}

In the glossary of administrative terms, empowerment refers to "granting powers to employees so that they can determine work objectives and performance methods, make decisions and have control on the required resources within the limits of their powers and responsibilities" (Glossary of administrative terms, 2007).

There are many definitions for the concept of empowerment. Al-Qahtani (2011) defined it as giving employees more powers, responsibilities and authority to make decisions and solve problems through performing work independently on their own way and without the direct involvement of the management. By providing adequate resources and appropriate working environment, accountability should be activated and employees should be responsible for their performance outcomes.

It is also defined as "giving individuals the freedom to make decisions through the delegation of authority, increasing participation and self-motivation, emphasizing the importance of teamwork, and providing an environment conducive to personal development and creativity" (Al-Bashabsha, 2008, p. 230).

According to (Hussein, 2011), empowerment is essential for the development of the performance of school principals, since it is the administrative approach through which they can carry out school activities and responsibilities and participate in school decision-making, thereby raising the level of motivation and achievement among principals. The foundations of the administrative empowerment process include the delegation of authorities and responsibilities, participation of employees in the decision-making process, organizational structure and regulation and affording the training required for employee development.

\subsection{Significance of Empowerment}

Hardworking is the best way to ensure success in achieving the desired performance of the organization. With the increased global competition and the continued need for business improvement, hardworking is no longer enough. In many cases, intelligent work is required, which means affording the new and advanced technology to the work environment. However, any institution can afford or imitate the advanced technology. Here, the significance of employee empowerment appears, as the best way for creativity, initiative and innovation. Though empowerment is the most essential elements of intelligent work as it assures quality and improves productivity, it is lost in most modern work environment. Empowerment means the involvement of employees through encouraging their creativity, independent thinking, taking initiatives and making decisions. Thus, it increases productivity and the level of the organization competitiveness.

The importance of empowerment is enhanced by the fact that the most effective decisions are made by the nearest individuals to the source of information, which leads to improving the service delivered by the staff to the customer directly.

Empowerment also increases the market share of the organization, as employees become more active and enthusiastic for work and customers become more satisfied because of employee rapid respond and problem solution without going back to the management (Hammoud \& Sheikh, 2010). In other words, empowerment motivates human resources to achieve the objectives of the organization. The organization success cannot be achieved without the cooperation of managers and employees. As the managers pave the way for the staff empowerment, the employees unleash their fullest potential and become ready to employ their information, experience and skills for achieving the objectives of the organization (Arrashoudi, 2009).

Through empowerment, organizations with high performance capabilities can be established by improving the organization productivity, competiveness and uniqueness. Through affording the appropriate training, employees can improve their skills, identify the needs of the organization, reduce costs through initiatives and creativity, improve quality and achieve profitability, productivity and adaptability to market changes. On the other hand, employees take advantage of empowerment through the increasing level of work satisfaction, having control over the daily tasks, achieving independence, having self-confidence and acquiring new knowledge and skills (Adouri \& Saleh, 2009).

It can be concluded that administrative empowerment is of great significance for both the organization and the employees. Through empowering the qualified staff, productivity, profitability and competitiveness are accomplished and success can be attained. Empowerment is the way to raise both job satisfaction among employees and service satisfaction among customers.

\subsection{The Dimensions of Administrative Empowerment}

The literature on administrative empowerment indicates to delegation of authority, self-motivation, teamwork, personal development and effective communication as the most basic dimensions of empowerment (Adouri \& 
Saleh, 2009; Almaani \& Akhu Arshedah, 2009). Delegation of authority includes assigning tasks and granting powers to subordinates, so that they can accomplish the set objectives and perform work without going back to their managers. Consequently, subordinates assume responsibility for the acceptable performance of the assigned tasks. Self-motivation can be accomplished by a good incentive system that attracts individuals, meets their needs, enhances work continuity, stimulates competition and affords a positive organizational climate, which contributes to raising job satisfaction and organizational loyalty. Teamwork results in providing a highly motivating work environment, suitable working atmosphere, quick response to technological changes and decision quality assurance. Before empowering employees, managers should be sure of their competencies. Personal development of employees can be afforded through providing the adequate training that aims at gaining the full knowledge, skill and tools necessary for performing work and actual conduct in the best way possible (Azamili, 2013). Effective communication with administrative institutions is one of the basic keys to empowering employees. To solve a problem, the management needs to collect information about the problem and contact the concerned individuals. In other words, effective communication helps solve problems through engaging the responsible individuals and thus activating empowerment (Al-Qahtani, 2011).

In the school context, administrative empowerment requires affording the appropriate organizational structures and regulations. Confidence, communication, delegation, information access, incentives, teamwork and participation in decision-making are the foundations of the culture of empowerment and the basis of forming teamwork willing to accomplish the desired performance outputs.

\subsection{Characteristics of Empowerment}

Empowerment increases the powers and responsibilities of the leaders and their ability to solve work problems and to face challenges. It activates accountability, responsibility and teamwork. Empowered employees are less dependent on the administration in managing the business (Abu Ali, 2010). In the school context, all the foregoing elements should be the foundation of the culture of empowerment in the educational institutions' environment to enable the empowerment of administrators.

\subsection{Administrative Empowerment in the Educational Institutions}

Recently, the Ministry of Education in Saudi Arabia has paid more attention to administrative empowerment. The Conference of Administrative Leadership held in Riyadh in 2014 laid an emphasis on the significance of administrative empowerment. In a seminar on the trends and needs of scientific research in the field of public education development in Saudi Arabia, Adduraihim (2014) asserted that empowering the supportive cadre is the way to achieve the strategic vision of the Ministry of Education. The strategic foundations for the future vision of public education development up to 2023 focus on empowering schools to manage the development process according to the circumstances of each region (Adbeai, 2014).

In Saudi schools, numerous administrators are regularly appointed, as one of the main pillars of school management. Administrative empowerment is the way to reduce administrative bureaucracy and enhance participation to improve services and performance (The organizational guide for public schools, 2013).

The tasks entrusted to the school principal require assigning some tasks to the school administrators, as the role of the school principal is to supervise and follow-up work in the school. They also participate in raising ideas and proposals and making decisions that contribute to the achievement of the school objectives and meet the empowerment requirements. Accordingly, unleashing the potentials of school administrators through training and delegation is the way for effective and continuous administrative improvement and school success. Empowerment of school administrators should go in line with trusting in their performance, freedom to choose the best way of task implementation, focus on the results, and appreciation of their efforts. Administrators are able to handle multiple administrative tasks in the school and contribute to the performance of tasks quickly and with high quality. It also relieves the burden on the school principal, as the empowered administrators represent one team contributes to the development of the school and the achievement of its objectives.

\section{Methodology and Procedures}

\subsection{Method}

The descriptive survey and comparative approach are adopted in the current study. Abdullah et al. (2007) stated that the descriptive survey is used to investigate the study sample in order to describe the phenomenon in question, while the comparative descriptive approach is applied to identify the possible causes that affect the phenomenon in question by comparison. 


\subsection{Population}

The study population consists of all the recently employed administrators in the intermediate schools of Riyadh Al-Khabra, compromising (89) ones, according to the statistics of the Ministry of Education, Saudi Arabia (Ministry of Education, 2014).

\subsection{Sample}

Complete census of the study population is applied. The sample consists of the recently employed administrators in the intermediate schools of Riyadh Al-Khabra, compromising (89) ones (Ministry of Education, 2014).

\subsection{Instrument}

After consulting the literature related to the study objectives and questions, the questionnaire is adopted as the study instrument. It consists of preliminary data on the study sample, which is the academic qualification and five domains compromising delegation of authority (8) items, self-motivation (10) items, teamwork (9) items, personal development (10) items and effective communication (9) items. The scale degrees are always, often, sometimes, rarely and never, as shown in Table 1.

Table 1. Response means and the corresponding scores

\begin{tabular}{lc}
\hline Degree & The arithmetic mean limit \\
\hline Always (very high empowerment) & $4.20-5$ \\
Often (high empowerment) & $4.19-3.40$ \\
Sometimes (medium empowerment) & $3.39-2.60$ \\
Rarely (low empowerment) & $2.59-1.80$ \\
Never (very low empowerment) & $1.79-1$ \\
\hline
\end{tabular}

Psychometric properties of the questionnaire:

Face validity:

To check the validity of the questionnaire, it was submitted to 15 examiners and the required modifications were done.

Internal validity:

To ensure the internal validity, the questionnaire was applied to a pilot sample consisting of 25 administrators. Pearson correlation coefficients between each item and the total score of its domain were calculated. It revealed a positive and strong correlation between the items of each domain and the total score of the domain, indicating the validity of the scale.

Structural validity of the study domains:

Pearson correlation coefficients between the average of each domain and the average of all the items of the questionnaires were calculated. It resulted in a strong and positive correlation between the average of each domain and the average of the questionnaire items, indicating the structural validity of the study domains.

\section{Reliability:}

After applying the questionnaire to the pilot study, Alpha Cronbach coefficient was applied to each domain of the study and all the domains. The value of the first domain was 0.77 , the second was 0.94 , the third was 0.89 , the fourth was 0.71 and the fifth domain was 0.86 . The reliability coefficient obtained 0.96 , indicating the high reliability and validity of the questionnaire.

Academic qualification:

To identify the academic qualification of the participants, frequency and percentage were applied.

Table 2. Distribution of participants according to academic qualification

\begin{tabular}{ccc}
\hline Academic qualification & Frequency & Percentage (\%) \\
\hline BA & 22 & 32.8 \\
Diploma of Middle Colleges & 10 & 14.9 \\
Teacher Training Institutes & 35 & 52.3 \\
Total & 67 & 100.0 \\
\hline
\end{tabular}




\section{Results and Discussion}

To answer the first question, the arithmetic means and standard deviations of the dimensions of empowerment: delegation of authority, self-motivation, teamwork, personal development and effective communication, as shown in Table 3.

Table 3. Arithmetic means and standard deviations of the dimensions of administrative empowerment

\begin{tabular}{lccccc}
\hline $\mathrm{S}$ & Domain & Arithmetic mean & Standard deviation & Rank & Degree of empowerment \\
\hline 1 & Delegation of authority & 3.46 & 0.841 & 1 & High \\
2 & Self-motivation & 2.56 & 0.899 & 4 & Low \\
3 & Teamwork & 3.02 & 0.887 & 2 & Medium \\
4 & Personal Development & 2.50 & 0.866 & 5 & Low \\
5 & Effective Communication & 2.84 & 0.873 & 3 & Medium \\
Administrative Empowerment as a whole & 2.85 & & & Medium \\
\hline
\end{tabular}

Table 3 shows that the arithmetic means for the dimensions of empowerment ranged from 2.50 to 3.46 , i.e. between high and low degree of empowerment. The reality of administrative empowerment as a whole reached 2.85 , i.e. a medium degree of empowerment. The delegation of authority was the highest dimension of empowerment with an average of (3.46), and personal development got the last rank with an average of (2.50). The reality of administrative empowerment as a whole obtained a medium degree, indicating the need to empower and support administrators through activating the delegation of authority and circulation of information.

The result can be interpreted that school principals need to know the requirements of activating empowerment. The appointment of administrators in intermediate schools is a new incident and the principals do not have the required knowledge to exercise empowerment. Lack of communication with the recently employed administrator and teamwork is another possible cause especially that there is a large time gap between them. Lack of training on the technical and administrative skills necessary for contemporary work among the recently employed administrators interprets their medium level of empowerment.

The result is consistent with Alfaez (2014), Alattar (2012) and Almaani and Akhu Arshedah (2009), where the degree of empowerment was medium. It is inconsistent with Adbeai (2014), as the degree of empowerment was high and Ashalan and Kaki (2014) and Comm and Mathaisel (2005), as the degree of empowerment was low.

To identify the degree of administrative empowerment among the recently employed administrators in the intermediate schools in Riyadh Al-Khabra from their viewpoint, the arithmetic means and standard deviations of the items of the study domains were calculated.

1) Delegation of authority

The arithmetic means and standard deviations of the items of this domain were calculated and ranked in a descending order. Table 4 shows the results.

Table 4. Arithmetic means, standard deviations and ranks of the items of delegation of authority by the school principal to the recently employed administrators from their viewpoints

\begin{tabular}{|c|c|c|c|c|c|}
\hline No. & Item & $\begin{array}{l}\text { Arithmetic } \\
\text { means }\end{array}$ & $\begin{array}{l}\text { Standard } \\
\text { deviation }\end{array}$ & Ranking & $\begin{array}{c}\text { Degree of } \\
\text { empowerment }\end{array}$ \\
\hline 1 & I have been delegated sufficient authority to do job tasks & 4.07 & 1.119 & 1 & High \\
\hline 2 & Tasks are delegated to me in writing & 3.70 & 1.360 & 3 & High \\
\hline 3 & There is a weekly follow-up on my delegated work & 2.93 & 1.363 & 7 & Medium \\
\hline 4 & $\begin{array}{l}\text { Additional tasks are delegated to me because of trust in my } \\
\qquad \text { capabilities }\end{array}$ & 3.75 & 1.531 & 2 & High \\
\hline 5 & Additional tasks are delegated to me according to my willing & 3.63 & 1.423 & 4 & High \\
\hline 6 & I perform the delegated tasks with flexibility & 3.28 & 1.444 & 6 & Medium \\
\hline 7 & I can make decisions independently & 2.75 & 1.210 & 8 & Medium \\
\hline 8 & $\begin{array}{l}\text { I take responsibility for my decisions in accordance with the } \\
\text { authority delegated to me }\end{array}$ & 3.57 & 1.351 & 5 & High \\
\hline & The reality of delegation of authority as a whole & 3.46 & 0.841 & & High \\
\hline
\end{tabular}


Table 4 indicated that the arithmetic means for the items of delegation of authority were (4.07-2.75), i.e. it ranged between a medium and high degree of empowerment. The item (I have been delegated sufficient authority to do job tasks) ranked first with a high degree, indicating administrators' satisfaction with the authority delegated to them to perform the tasks sufficiently. The item (I can make decisions independently) got the last rank with a medium degree, indicating that the school principals trust them to perform the assigned work. The reality of delegation of authority obtained a high degree, with a general mean of 3.46 and a standard deviation of 0.841 , indicating that the recently employed administrators have a similar vision of the authority delegated by the principal. It means that school principals delegate authority to administrators, as a result of their trust in the administrators' ability to carry out the assigned tasks. In addition, delegation of authority relieves some of the work burden imposed on the school principal. It also helps identify the capabilities of the administrators and encourage them to do the best performance. The result is consistent with Alattar (2012), indicating a high degree of delegation by the school principals. It is inconsistent with Jabir (2012) and Anafisah (2011), where delegation obtained a medium degree.

2) Self-Motivation

Table 5 indicates the results.

Table 5. Arithmetic means, standard deviations and ranks of the items of self-motivation by the school principals to the recently employed administrators from their viewpoints

\begin{tabular}{|c|c|c|c|c|c|}
\hline No. & items & $\begin{array}{l}\text { Arithmetic } \\
\text { means }\end{array}$ & $\begin{array}{l}\text { Standard } \\
\text { deviation }\end{array}$ & Ranking & $\begin{array}{c}\text { Degree of } \\
\text { empowerment }\end{array}$ \\
\hline 1 & Appreciating my efforts at work & 3.40 & 1.558 & 1 & High \\
\hline 2 & Praising my determination to work & 2.93 & 1.306 & 3 & Medium \\
\hline 3 & Immediate feedback on my outstanding performance & 2.61 & 1.337 & 4 & Medium \\
\hline 4 & Enhancing personal accountability & 2.51 & 1.319 & 5 & Low \\
\hline 5 & Applying the proposals I develop to address work problems & 2.42 & 1.269 & 7 & Low \\
\hline 6 & Promoting creativity & 2.15 & 1.104 & 8 & Low \\
\hline 7 & Help develop my work skills & 2.51 & 1.307 & 6 & Low \\
\hline 8 & Adding activities of personal value & 1.97 & 1.180 & 10 & Low \\
\hline 9 & Allowing me to achieve the school goals & 2.15 & 1.004 & 9 & Low \\
\hline 10 & $\begin{array}{c}\text { Encouraging my performance of extra tasks with love and } \\
\text { personal motivation }\end{array}$ & 2.94 & 1.028 & 2 & Medium \\
\hline & The reality of self-motivation as a whole & 2.56 & 0.899 & & Low \\
\hline
\end{tabular}

Table 5 indicates that the arithmetic means of the items of self-motivation ranged from 3.40 to 1.97, i.e. between a low and high degree of empowerment. The item (Appreciating my efforts at work) ranked first with a high degree of empowerment. It indicates that school principals are aware of the importance of evaluating the efforts done by the administrators and its effects on achievement and productivity. The item (Adding activities of personal value) got the last rank with a low degree of empowerment. It can be interpreted that the school principal underestimates the value of additional activities in motivating administrators. The overall mean of self-motivation was 2.56 with a low degree of empowerment and a standard deviation of 0.899 , indicating a homogenous vision of self-motivation among the recently employed administrators. The school principal may encourage them, but may not have the authority to give them incentives. The result is consistent with Ashalan and Kaki (2014), and inconsistent with Masoud (2012) which obtained a medium degree of self-motivation among administrators.

3) Teamwork

Table 6 explains the results. 
Table 6. Arithmetic means, standard deviations and ranks of the items of teamwork by the school principals to the recently employed administrators from their viewpoints

\begin{tabular}{|c|c|c|c|c|c|}
\hline No. & items & $\begin{array}{c}\text { Arithmetic } \\
\text { means }\end{array}$ & $\begin{array}{l}\text { Standard } \\
\text { deviation }\end{array}$ & Ranking & $\begin{array}{c}\text { Degree of } \\
\text { empowerment }\end{array}$ \\
\hline 1 & Providing an cooperative work environment & 3.22 & 1.253 & 1 & Medium \\
\hline 2 & Applying justice system & 3.19 & 1.258 & 2 & Medium \\
\hline 3 & Enhancing sense of belonging among the team members & 3.16 & 1.123 & 3 & Medium \\
\hline 4 & Preferring teamwork to individual performance & 2.84 & 1.163 & 8 & Medium \\
\hline 5 & Encouraging teamwork initiatives & 2.94 & 0.983 & 7 & Medium \\
\hline 6 & $\begin{array}{l}\text { Encouraging participation in a specific work to achieve the } \\
\text { school goals }\end{array}$ & 2.79 & 1.200 & 9 & Medium \\
\hline 7 & $\begin{array}{l}\text { Giving the teamwork authority commensurate with their } \\
\text { tasks }\end{array}$ & 2.99 & 1.108 & 6 & Medium \\
\hline 8 & $\begin{array}{l}\text { Facilitating the tasks assigned to the teamwork by } \\
\text { implementing their decisions }\end{array}$ & 3.09 & 0.866 & 4 & Medium \\
\hline 9 & I ask my colleagues when needed to complete some tasks & 3.00 & 1.291 & 5 & Medium \\
\hline & The reality of teamwork as a whole & 3.02 & 0.887 & & Medium \\
\hline
\end{tabular}

Table 6 shows that the arithmetic means of the items of teamwork ranged from 3.22 to 2.79 with a medium degree of empowerment. The item (Applying justice system) ranked first with a medium degree, indicating that the school principal distributes tasks evenly among the team members. The item (Encouraging participation in a specific work to achieve the school goals) got the last rank with a medium of empowerment, indicating that the process of developing school performance is a collective responsibility achieved only through collective efforts cooperation between administrators in benefiting from the available facilities in the school. The overall mean of teamwork was 3.46 with a medium degree of empowerment and a standard deviation of 0.841 , indicating a homogenous vision of teamwork among the recently employed administrators. This result can be interpreted that the school principal does not recognize the importance of teamwork for achieving the school goals and the need to strengthen and improve methods and standards of administrators' participation and cooperation. The result is consistent with Almaani and Akhu Arshedah (2009), where teamwork got a medium degree of empowerment, and inconsistent with Jabir (2012) and Alattar (2012).

4) Personal development

Table 7 illustrates the results.

Table 7. Arithmetic means, standard deviations and ranks of the items of personal development by the school principals to the recently employed administrators from their viewpoints

\begin{tabular}{|c|c|c|c|c|c|}
\hline No. & items & $\begin{array}{c}\text { Arithmetic } \\
\text { means }\end{array}$ & $\begin{array}{l}\text { Standard } \\
\text { deviation }\end{array}$ & Ranking & $\begin{array}{c}\text { Degree of } \\
\text { empowerment }\end{array}$ \\
\hline 1 & I have a sense of security and stability & 3.27 & 0.994 & 1 & Medium \\
\hline 2 & I achieve professional development & 2.91 & 1.083 & 2 & Medium \\
\hline 3 & Directing me to ways of personal development & 2.70 & 1.078 & 4 & Medium \\
\hline 4 & Affording learning opportunities to gain new knowledge & 2.82 & 1.043 & 3 & Medium \\
\hline 5 & Affording diverse methods of career development & 2.58 & 1.075 & 5 & Low \\
\hline 6 & $\begin{array}{l}\text { Providing training programs for skills development and } \\
\text { practical applications }\end{array}$ & 2.30 & 1.181 & 6 & Low \\
\hline 7 & Adopting a comprehensive management training plan & 2.24 & 1.232 & 7 & Low \\
\hline 8 & Providing periodic reports on my performance & 2.03 & 1.381 & 9 & Low \\
\hline 9 & Motivational self-development using incentives & 2.24 & 1.280 & 8 & Low \\
\hline 10 & Directing me to improve my weaknesses & 1.87 & 0.983 & 10 & Low \\
\hline \multicolumn{2}{|c|}{ The reality of personal development as a whole } & 2.50 & 0.866 & & Low \\
\hline
\end{tabular}

Table 7 shows that the arithmetic means of the items of personal development ranged between (3.27 - 1.87), i.e. between a medium and low degree of empowerment. Item (I have a sense of security and stability) ranked first with a medium degree of empowerment. It indicates that the school principal is aware of the importance of having 
a sense of stability in the work environment among administrators and its impact on work continuity and productivity. The item (Directing me to improve my weaknesses) ranked last with a low degree of empowerment. It refers to the school's principal disinterestedness in diagnosing the level of administrators' performance and in providing them with regular feedback.

The overall average of personal development by the school principal for the recently employed administrators obtained a low degree, with an arithmetic mean of 2.50 and a standard deviation of 0.866 , indicating a homogenous vision of personal development among the recently employed administrators. It may be due to the school principal's lack of awareness of her role in improving and developing the personality of the administrators. Accordingly, the required training courses, workshops and meetings should be made available for both the principals and the administrators.

The result is consistent with Almaani and Akhu Arshedah (2009) and Alattar (2012), where personal development got a low degree and inconsistent with Jabir (2012) where the domain of training obtained a very high degree.

\section{5) Effective communication}

The results are shown in the following table.

Table 8. Arithmetic means, standard deviations and ranks of the items of effective communication by the school principals to the recently employed administrators from their viewpoints

\begin{tabular}{|c|c|c|c|c|c|}
\hline No. & items & $\begin{array}{c}\text { Arithmetic } \\
\text { means }\end{array}$ & $\begin{array}{l}\text { Standard } \\
\text { deviation }\end{array}$ & Ranking & $\begin{array}{c}\text { Degree of } \\
\text { empowerment }\end{array}$ \\
\hline 1 & Adopting open door policy & 3.07 & 1.159 & 2 & Medium \\
\hline 2 & Building relations in the school on mutual respect & 3.22 & 1.056 & 1 & Medium \\
\hline 3 & Clear explanation of work procedures & 2.93 & 1.063 & 4 & Medium \\
\hline 4 & $\begin{array}{l}\text { Having an information system that provides accurate } \\
\text { information quickly }\end{array}$ & 2.58 & 1.130 & 7 & Low \\
\hline 5 & $\begin{array}{l}\text { Providing effective communication channels for } \\
\text { information exchange }\end{array}$ & 2.46 & 1.133 & 9 & Low \\
\hline 6 & Using effective communication at different levels & 2.81 & 1.246 & 6 & Medium \\
\hline 7 & Attention to the integrity of verbal communication & 3.01 & 1.121 & 3 & Medium \\
\hline 8 & Employing of non-verbal communication media & 2.55 & 1.118 & 8 & Low \\
\hline 9 & Transparent dealing with administrators & 2.93 & 1.132 & 5 & Medium \\
\hline \multicolumn{2}{|c|}{ The reality of effective communication as a whole } & 2.84 & 0.873 & & Medium \\
\hline
\end{tabular}

As indicated in Table 8, the arithmetic means of the items of effective communication ranged from 3.22 to 2.46, i.e. between a medium and low degree of empowerment. The item (Building relations in the school on mutual respect) ranked first with a medium degree of empowerment. It can be attributed to underestimating the importance of relations to empowerment by the school principal. The item (providing effective communication channels for information exchange) ranked last with a low degree of empowerment. It can be interpreted that school principals impose constraints that hinder communication with management, in addition to the lack of using communication technology. The school principal's lack of awareness of the value of additional activities in stimulating administers is another possible explanation.

The overall average value of effective communication was low with a general mean of 2.84 and a standard deviation of 0.873 , indicating a homogenous vision of effective communication by the school principal among the recently employed administrators. It can be attributed to administrators' low level of satisfaction with the mechanisms used to provide the necessary work information and the lack of constantly updated databases.

The result is consistent with Anafisah (2011), asserting the weakness of communication systems and the exchange of information among administrators, and inconsistent with Jabir (2012) and Alattar (2012), where the degree of this domain is medium.

To answer the second question and the study hypothesis, ANOVA test was applied and the obtained results are presented in the following table. 
Table 9. Results of ANOVA test of the hypothesis

\begin{tabular}{|c|c|c|c|c|c|c|}
\hline Domain & Qualification & No. & arithmetic mean & standard deviation & P Value & significance \\
\hline \multirow{3}{*}{ Delegation of authority } & $\mathrm{BA}$ & 22 & 3.38 & 0.847 & \multirow{3}{*}{0.838} & \multirow{3}{*}{0.437} \\
\hline & Diploma of Middle Colleges & 10 & 3.78 & 0.577 & & \\
\hline & Teacher Training Institutes & 35 & 3.42 & 0.899 & & \\
\hline \multirow{3}{*}{ Self-motivation } & BA & 22 & 2.30 & 0.963 & \multirow{3}{*}{1.384} & \multirow{3}{*}{0.288} \\
\hline & Diploma of Middle Colleges & 10 & 2.73 & 0.890 & & \\
\hline & Teacher Training Institutes & 35 & 2.67 & 0.849 & & \\
\hline \multirow{3}{*}{ Teamwork } & BA & 22 & 2.65 & 0.801 & \multirow{3}{*}{3.484} & \multirow{3}{*}{$0.037 *$} \\
\hline & Diploma of Middle Colleges & 10 & 3.39 & 0.807 & & \\
\hline & Teacher Training Institutes & 35 & 3.16 & 0.900 & & \\
\hline \multirow{3}{*}{ Personal Development } & BA & 22 & 2.30 & 0.726 & \multirow{3}{*}{1.147} & \multirow{3}{*}{0.324} \\
\hline & Diploma of Middle Colleges & 10 & 2.78 & 0.954 & & \\
\hline & Teacher Training Institutes & 35 & 2.54 & 0.915 & & \\
\hline \multirow{3}{*}{ Effective Communication } & BA & 22 & 2.74 & 0.791 & \multirow{3}{*}{0.327} & \multirow{3}{*}{0.722} \\
\hline & Diploma of Middle Colleges & 10 & 3.01 & 0.885 & & \\
\hline & Teacher Training Institutes & 35 & 2.85 & 0.932 & & \\
\hline \multirow{3}{*}{$\begin{array}{l}\text { Total } \\
\text { empowerment }\end{array}$} & BA & 22 & 2.64 & 0.724 & \multirow{3}{*}{1.440} & \multirow{3}{*}{0.244} \\
\hline & Diploma of Middle Colleges & 10 & 3.11 & 0.734 & & \\
\hline & Teacher Training Institutes & 35 & 2.90 & 0.805 & & \\
\hline
\end{tabular}

* Significant at the level of 0.05 .

Table 9 shows that there are no statistically significant differences among the recently employed administrators attributed to the academic qualification variable as the level of significance in delegation of authority was 0.437 , self-motivation (0.288), personal development (0.324) and effective communication (0.722), which are insignificant values at the level of $(\alpha \leq 0.05)$. There are statistically significant differences among the recently employed administrators attributed to the academic qualification variable in the degree of teamwork, which got a significance level value of (.037 in ANOVA test. There are no statistically significant differences among the recently employed administrators attributed to the academic qualification variable in the degree of administrative empowerment as a whole, as the significance level value in ANOVA test was (0.244), i.e. insignificant value at the level of $(\alpha \leq 0.05)$.

To sum up, the academic qualification variable did not affect the degree of administrative empowerment, except for teamwork, from administrators' perspective. On one hand, the need for empowerment was felt by all the administrators regardless of their academic qualification. On the other hand, administrative empowerment by the school principal was a random process, as they did not consider the administrator' academic qualification. The result is consistent with Ashalan and Kaki (2014) and Adbeai (2014), concluding that academic qualification does not affect the degree of administrative empowerment. It is inconsistent with Alfaez (2014), which resulted in a significant difference in favor of the higher academic qualification in university context.

As there is a significant difference in the views of the recently employed administrators in the teamwork degree, Schiffe test was applied as follows:

Table 10. Results of Schiffe test to identify the direction of differences in the viewpoints of the recently employed administrators in the degree of teamwork due to academic qualification variable

\begin{tabular}{lccccc}
\hline Domain & Qualification & Average & BA & Diploma of Middle Colleges & Teacher Training Institutes \\
\hline \multirow{4}{*}{ Teamwork } & BA & 2.65 & $-0.74242^{*}$ & $-0.51227^{*}$ \\
& Diploma of Middle Colleges & 3.39 & & \\
& Teacher Training Institutes & 3.16 & & \\
\hline
\end{tabular}

* Significant at the level of 0.05 .

Table 10 shows that the differences in the viewpoints of the recently employed administrators in the intermediate schools in Riyadh Al-Khabra in the degree of teamwork due to the academic qualification variable were among the holders of BA, Middle Colleges diploma and teacher's institute, favoring the holders of Middle Colleges diploma and Teacher Training Institutes. It can be interpreted that the holders of Middle Colleges diploma and teacher's 
institute are involved in teamwork for training and gaining experience, while the holder of BA can work alone efficiently.

The result is consistent with Ashalan and Kaki (2014), Asuwai and Atta'ani (2013), Jabir (2012), Masoud (2012) and Almaani and Akhu Arshedah (2009), concluding that the academic qualification variable has an impact on teamwork, and inconsistent with Alfaez (2014), Adbeai (2014) and Anafisah (2011).

Accordingly, the study hypothesis is accepted.

\section{Conclusion}

There is a medium level of administrative empowerment among the recently employed administrators in the intermediate schools of Riyadh Al-Khabra. There are statistically significant differences in the averages of the degree of administrative empowerment among the recently employed administrators in the intermediate schools of Riyadh Al-Khabra in the degree of teamwork attributed to academic qualification. There are no statistically significant differences in the averages of the degree of administrative empowerment as a whole among the recently employed administrators in the intermediate schools of Riyadh Al-Khabra attributed to academic qualification.

\section{Recommendations}

In the light of the study results, enhancing the application of administrative empowerment among administrators in schools can be conducted through creating an organizational structure supportive of the application of the concept of administrative empowerment. Disseminating the culture of empowerment in the educational field and diagnosing its organizational constraints help define a clear vision to empower the recently employed administrations. Administrators should be prepared and qualified through affording the necessary training courses, lectures, seminars and meetings. School principals should play a role in enhancing administrative empowerment through boosting confidence among administrations, encouraging teamwork and activating accountability. They also can show moral support to administrators by trusting their abilities and appreciating their efforts; thus enhancing their sense of self-efficacy. Opening channels of communication between administrators and the concerned educators enables the circulation of information necessary to perform the work. Officials of the Ministry of Education have to reconsider the incentive system, administrative titles, job descriptions and privileges according to academic qualifications.

\section{Future Studies}

Future studies in the field of administrative empowerment may deal with:

1) The reality of administrative empowerment after the integration of public education and higher education.

2) The reality of technical empowerment of administrators in educational institutions.

3) Empowerment of schools in the light of institutional accreditation standards.

4) Training requirements for administrators based on academic qualification.

\section{References}

Abdul Khaliq, T. (2011). The impact of empowerment on organizational citizenship behaviors, case study on a banking institution in Egypt (Unpublished $\mathrm{PhD}$ dissertation). Ain Shams University, Cairo.

Abdullah, A., Abdul Wahab, F., \& Suleiman, A. (2007). Introduction to research in education and psychology. Riyadh: Al-Rashed Library.

Abu Ali, W. H. (2010). The degree of practicing the dimensions of administrative empowerment among secondary school principals and its relation to administrative development. Journal of Childhood and Education, 5, 436-456.

Adbeai, S. (2014). The reality of the administrative empowerment among public school principals in Riyadh in light of the strategy of developing public education in Saudi Arabia (MA thesis, Imam Muhammad bin Saud Islamic University, Riyadh).

Adduraihim, N. (2014). Trends and needs of scientific research in the field of general education development. Center for Research Excellence, King Saud University. Retrieved from http://www.youtube.com/watch?v=ef7TQMfdCLg

Adouri, Z., \& Saleh, A. (2009). Empowerment management and economics of trust in the third millennium business organizations. Jordan: Al-Yazuri House for Scientific Publishing and Distribution.

Alattar, M. (2012). The extent of practicing administrative empowerment and its impact on the staff creativity: A comparative study of the views of employees of Al-Azhar and Islamic University in Gaza (MA thesis, 
Islamic University, Gaza).

Al-Bashabsha, S. (2008). The impact of administrative empowerment on enhancing organizational creativity among the staff of Aqaba special economic zone authority. Arab Journal of Administrative Sciences, 15(2).

Alfaez, H. (2014). Administrative empowerment of leaders in Saudi universities: Reality and challenges. The conference of government administrative leaders, Institute of Public Administration, Riyadh.

Almaani, A., \& Akhu Arshedah, A. (2009). Empowerment and its Impact on staff Creativity in Jordanian University: A Field Study Analysis. Jordanian Journal of Business Administration, 5(2), 234.

Al-Qahtani, M. (2011). Administrative empowerment among educational Leaders in Schools between Conceptualization and Degree of Practice (MA thesis, Arab Open University, Jeddah).

Anafisah, M. (2011). Empowerment and its relationship to job satisfaction, a field study of administrative staff viewpoints at King Saud University (Unpublished MA thesis). King Saud University, Riyadh.

Arraqab, A. (2010). The relationship between transformational leadership and staff empowerment in Palestinian universities in the Gaza Strip (Unpublished MA thesis). Al-Azhar University, Gaza.

Arrashoudi, K. (2009). Empowerment principles in the educational security organizations and their readiness for application (Unpublished MA thesis). Naif Arab University for Security Sciences.

Ashalan, M., \& Kaki, S. (2014). Mechanisms of activating empowerment to achieve performance quality of at Princess Norah University. Saudi Journal of Higher Education, 37, 10-72.

Asuwai, O., \& Atta'ani, H. (2013). Administrative empowerment and its relation to job satisfaction among public school principals in Dammam, Saudi Arabia. Journal of Studies of Educational Sciences, 40(1), 305.

Azamili, Y. (2013) Empowerment and its relationship to the administrative creativity of the principals of UNRWA schools in the Gaza Strip (MA thesis, Islamic University, Gaza).

Comm, C., \& Mathaisel, D. (2005). A case study in applying lean sustainability concepts to universities. International Journal of Sustainability in Higher Education, 6(2), 134-146. https://doi.org/10.1108/14676370510589855

Glossary of administrative terms. (2007). Cairo: Arab Organization for Administrative Development.

Hamoud, K., \& Sheikh, R. (2010). Quality management in distinguished organizations. Jordanian Journal of Business Administration, 5(236), 2-240.

Hussein, S. (2011). Empowerment and its role in the development of administrative leadership. Journal of the successful director, 136, 13-17.

Jabir, Z. (2012). The reality of administrative empowerment among the principals of secondary schools in Jeddah educational area (Unpublished MA thesis). Department of Educational Administration and Planning, Faculty of Education, Umm Al-Qura University, Makkah.

Lau, W. K. (2010). Empowerment of non-academic personal in higher education: Exploring associations with perceived organizational support for innovation and organizational trust ( $\mathrm{PhD}$ dissertation). The University of Iowa. https://doi.org/10.17077/etd.nualb3wl

Massoud, M. (2012). The degree of administrative empowerment and performance development from public school principals' viewpoint in the northern governorates of the West Bank (MA thesis). Al-Najah National University, Palestine.

Ministry of Education. (2013). The Organizational guide for public education schools. Riyadh: King Fahad National Library.

Ministry of Education. (2014). Statistics of personnel for the occupants of administrative jobs, administrators category. Al-Qassim: Education Office in Riyadh Al-Khabra.

Mulham, Y. (2009). Empowerment: A contemporary management concept. Arab Organization for Administrative Development, Jordan.

Weshah, H. A. (2012). The Perception of empowerment and delegation of authority by teachers in Australian and Jordanian schools: A Comparative Study. European Journal of Social Sciences, 31(3), 359-375. 


\section{Copyrights}

Copyright for this article is retained by the author(s), with first publication rights granted to the journal.

This is an open-access article distributed under the terms and conditions of the Creative Commons Attribution license (http://creativecommons.org/licenses/by/4.0/). 